\title{
An Innovative Appraisal of Psychopathology in Extant Criminological Psychiatry
}

\author{
Saeed Shoja Shafti* \\ Professor of Psychiatry, Razi Psychiatric Hospital, Tehran, Iran \\ *Corresponding author: Saeed Shoja Shafti, Professor of Psychiatry, Razi Psychiatric Hospital, Tehran, Iran
}

ARTICLE INFO

Received: 幽 June 16, 2021

Published: 幽 July 01, 2021

Citation: Saeed Shoja Shafti. An Innovative Appraisal of Psychopathology in Extant Criminological Psychiatry. Biomed J Sci \& Tech Res 36(5)-2021. BJSTR. MS.ID.005923.

Keywords: Forensic Psychiatry; Clinical-Legal Issues in Psychiatry; Psychopathology; Bizarre or Non-Bizarre Delusion; Delusional Disorder; Frame-Up Psychosis; Fake Psychiatric Disorder; Furtive Ploys

\begin{abstract}
SUMMARY
Jaspers regarded a delusion as a perverted view of reality that is incorrigibly held. According to him, delusions have three components: They are held with unusual conviction and are not amenable to logic; meanwhile the absurdity or erroneousness of their content is manifest to other people. While Norman Cameron's pseudo-community, a supposed community of conspirators, was a historical description about conditions that favor the development of delusional disorders, modern technology and advancement of new communicative tools, like smart phone, hidden camera, satellite, internet, stealthy or scheming tricks and setups, like double-crossing and masquerading scenarios, stressful circumstances, furtive or hectic arrangements, creating a scene to deceive, hack, or tampering, have brought about an increasing possibility of conspiracy by prejudiced or inimical people, which may amplify the conceivable diagnostic faults by more curbing of examiner's vigilance. On the other hand, it is the duty of forensic and clinical psychiatrist to discover any kind of deceptive entrapment or simulation. In the present article, such eccentricities, which may have come about in new time, have been discussed briefly, especially with respect to Paranoia and Paranoid ideation, and some solutions for better demarcation of the pertained problems and completion of psychopathological operational definitions have been suggested, incidentally, for defending the individuals' civil rights.
\end{abstract}

\section{Introduction}

Modern technology and advancement of new communicative tools, like smart phone, hidden camera, satellite, internet, plus stealthy or scheming tricks and setups, like double-crossing and masquerading scenarios, stressful circumstances, furtive or hectic arrangements, creating a scene in order to deceive, hack, or tampering, by criminals or spies during undercover activities, which are visible, audible, or readable, too, in everyday big screen's movies, small screen's serials, radio set, periodicals, and novels, respectively, don't seem to spare psychopathology, which has been formulated descriptively, based on phenomenological dimensions [1], during preceding eras, without availability of any of the aforesaid innovations. Forensic psychiatry, too, which is based merely on the said dimensions, as like as its clinical matching part in typical mental health settings, could not be faultless, when no robust biological foundation has been developed, so far, for psychiatric diagnosis [2]. Thus, it is assumable that current scientific and industrial progressions may have amplified the said diagnostic faults by more curbing of clinician's vigilance, which has been framed by old conceptions. In the present article, such eccentricities, which may have come about in new time, about several psychiatric signs and symptoms, have been discussed briefly, especially with respect to Paranoia and Paranoid ideation (Table 1) and some solutions for better demarcation of the pertained problems and completion of psychopathological operational definitions have been suggested, incidentally, for defending the individuals' civil rights. 
Table 1: Some psychiatric signs and symptoms that may be simulated or stirred by stealthy or scheming tricks and setups, like double-crossing and masquerading scenarios, stressful circumstances, furtive arrangements, creating a scene to deceive, hack, or tampering.

\begin{tabular}{|c|c|}
\hline Sign or symptom & Definition \\
\hline Delusion of persecution & $\begin{array}{l}\text { False belief of being harassed or persecuted; often found in litigious patients who have a pathological } \\
\text { tendency to take legal action because of imagined mistreatment. Most common delusion }\end{array}$ \\
\hline Delusion of control & False belief that a person's will, thoughts, or feelings are being controlled by external forces \\
\hline Passivity of thought & patients may experience that their thoughts are being controlled \\
\hline Passivity of emotion & the affect that the patient experiences does not seem to him to be his own and he has been made to feel it \\
\hline Passivity of impulse & $\begin{array}{l}\text { the patient experiences a drive, which he feels is alien, to carry out some motor activity. The impulse may be } \\
\text { experienced without the subject carrying out the behavior }\end{array}$ \\
\hline Passivity of volition & the patient feels that it is not his will that carried out the action \\
\hline Delusion of infidelity & False belief that one's lover is unfaithful. Sometimes called pathological jealousy \\
\hline Delusion of reference & $\begin{array}{c}\text { False belief that the behavior of others refers to oneself or that events, objects, or other people have a } \\
\text { particular and unusual significance, usually of a negative nature; derived from idea of reference, in which } \\
\text { persons falsely feel that others are talking about them (e.g., belief that people on television or radio are talking } \\
\text { to or about the person) }\end{array}$ \\
\hline Idea of reference & $\begin{array}{l}\text { Misinterpretation of incidents and events in the outside world as having direct personal reference to oneself; } \\
\text { occasionally observed in normal persons, but frequently seen in paranoid patient }\end{array}$ \\
\hline Erotomania & $\begin{array}{c}\text { Delusional belief, more common in women than in men, that someone is deeply in love with them (also known } \\
\text { as de Clerambault syndrome) }\end{array}$ \\
\hline Fausse reconnaissance & False recognition, a feature of paramnesia. Can occur in delusional disorders \\
\hline Jolie a deux & $\begin{array}{l}\text { Mental illness shared by two persons, usually involving a common delusional system; if it involves three } \\
\text { persons, it is referred to as Jolie trois, etc. Also called shared psychotic disorder }\end{array}$ \\
\hline Hypervigilance & $\begin{array}{l}\text { Excessive attention to and focus on all internal and external stimuli; usually seen in delusional or paranoid } \\
\text { states }\end{array}$ \\
\hline $\begin{array}{l}\text { Delusional mood (delusional } \\
\text { atmosphere) }\end{array}$ & $\begin{array}{c}\text { Experiencing everything around as sinister, portentous, uncanny, peculiar in an indefinable way. While the } \\
\text { person knows that he personally is invaded but cannot tell how, he has a feeling of anticipation, sometimes } \\
\text { even of excitement, that soon all separate parts of his experience will fit together to reveal something } \\
\text { immensely significant }\end{array}$ \\
\hline Irritability & Abnormal or excessive excitability, with easily triggered anger, annoyance, or impatience \\
\hline Illogical thinking & $\begin{array}{l}\text { Thinking containing erroneous conclusions or internal contradictions; psychopathological only when it is } \\
\text { marked and not caused by cultural values or intellectual deficit }\end{array}$ \\
\hline Illusion & Perceptual misinterpretation of a real external stimulus \\
\hline Hallucination & $\begin{array}{l}\text { False sensory perception occurring in the absence of any relevant external stimulation of the sensory modality } \\
\text { involve. }\end{array}$ \\
\hline Impaired insight & Diminished ability to understand the objective reality of a situation \\
\hline Impaired judgment & Diminished ability to understand a situation correctly and to act appropriately \\
\hline Impulse control & Ability to resist an impulse, drive, or temptation to perform some action \\
\hline Irritable mood & State in which one is easily annoyed and provoked to anger. See also irritability \\
\hline Panic & $\begin{array}{l}\text { Acute, intense attack of anxiety associated with personality disorganization; the anxiety is overwhelming and } \\
\text { accompanied by feelings of impending doom }\end{array}$ \\
\hline Paranoid delusion & Includes persecutory delusions and delusions of reference, control, and grandeur \\
\hline Paranoid ideation & Thinking dominated by suspicious, persecutory, or grandiose content of less than delusional proportions \\
\hline Systematized delusion & Group of elaborate delusions related to a single event or theme \\
\hline Thought broadcasting & Feeling that one's thoughts are being broadcast or projected into the environment \\
\hline Xenophobia & Abnormal fear of strangers \\
\hline Capgras syndrome & the delusion that a familiar person has been replaced by an impostor \\
\hline Fregoli's phenomenon & the delusion that persecutors or familiar persons can assume the guise of strangers \\
\hline Voyeurism & $\begin{array}{l}\text { Voyeurism, also known as scopophilia, is the recurrent preoccupation with fantasies and acts that involve } \\
\text { observing unsuspecting persons who are naked or engaged in grooming or sexual activity. }\end{array}$ \\
\hline Telephone and computer scatologia & $\begin{array}{l}\text { Telephone scatologia is characterized by obscene phone calling and involves an unsuspecting partner. Persons } \\
\text { also use interactive computer networks, sometimes compulsively, to send obscene messages by electronic mail } \\
\text { and to transmit sexually explicit messages and video images }\end{array}$ \\
\hline
\end{tabular}




\begin{tabular}{|c|c|}
\hline Pedophilia & $\begin{array}{c}\text { Pedophilia involves recurrent intense sexual urges toward, or arousal by, children 13 years of age or younger, } \\
\text { over a period of at least } 6 \text { months }\end{array}$ \\
\hline Frotteurism & $\begin{array}{c}\text { Frotteurism is usually characterized by a man's rubbing his penis against the buttocks or other body parts of } \\
\text { a fully clothed woman to achieve orgasm. At other times, he may use his hands to rub an unsuspecting victim. } \\
\text { The acts usually occur in crowded places, particularly in subways and buses }\end{array}$ \\
\hline Substance abuse & The repeated use of a drug or chemical substance, with or without physical dependence \\
\hline
\end{tabular}

\section{Background}

Etiologically, practitioners have a strong clinical impression that many patients with delusional disorder are generally isolated and have reached less than anticipated levels of success [3]. Specific psychodynamic schemes about the source and development of delusional symptoms involve hypotheses about hypersensitive persons and specific ego mechanisms [4]. Freud, se well, believed that delusions, rather than being symptoms of the illness, are part of a restorative process [5]. Clinical observations show that many, if not all, paranoid patients experience a lack of trust in interactions. A theory connects this cynicism to a constantly unfriendly family environment. Erik Erikson's concept of trust versus mistrust in early development is a valuable model to describe the dubiousness of a paranoid person who never went through the healthy experience of having his or her needs fulfilled by what Erikson termed the "outer-providers" [6]. Thus, they have a general distrust of their environment [7]. Patients with delusional disorder use principally the defense mechanisms of projection, denial, and reaction formation. They use reaction formation as a defense against aggression, dependence needs, and feelings of affection, and transform the need for dependence into firm independence [8].

Patients use denial to avoid awareness of painful reality. Consumed with anger and hostility and unable to face responsibility for the rage, they project their resentment and anger onto others and use projection to protect themselves from recognizing unacceptable impulses in themselves [9]. On the other hand, delusions have been related to a range of additional factors such as social and sensory seclusion, socioeconomic deprivation, and character disruption [10]. Deaf and visually impaired persons and maybe refugees with restricted aptitude in a new language may be more exposed to delusion formation than the normal populace [11]. On the other hand, Norman Cameron designated seven conditions that favor the development of delusional disorders: an increased anticipation of receiving sadistic conduct, circumstances that increase mistrust and doubt, social seclusion, conditions that increase jealousy and envy, circumstances that lower self-confidence, conditions that cause people to see their own weaknesses in others, and conditions that increase the potential for reflection over probable motivations and meanings. When frustration from any amalgamation of these circumstances surpasses the bearable edge, people become anxious and withdrawn; they grasp that something is wrong, search for a clarification for the problem, and develop a delusional system as a resolution. Expansion of the delusion to include imagined people and attribution of nasty drives to both real and imagined people results in the construction of the pseudo-community-a supposed community of conspirators. This delusional object theoretically binds together projected desires and worries to rationalize the patient's hostility and to offer a real entity for the patient's antagonisms [3].

Psychodynamic models, as well, postulate that persecutory delusions are a defensive psychological reaction to conflicts or stresses that represent an intense hazard to the self [12]. In reacting to the said danger, there is an emotional withdrawal from close connections and an extreme struggle to keep the form of normality by defensive mechanisms such as projection [13]. As a last point, the paranoid defense cannot relieve worry and intensifies to a discrete maladaptive state, which is assumed to end into a delusional disorder [14]. An additional scheme of the etiology of delusional disorder is based on study by cognitive psychologists and proposes that individuals with persecutory delusions selectively turn their attention to intimidating data, jump to inferences by inadequate evidence, attribute bad happenings to peripheral personal sources, and have trouble in imagining others' purpose and drives [15]. Favored recollection of bullying incidents has, likewise, been hypothesized as a mechanism for strengthening the delusional conviction [16]. Anyhow, the exact etiology of delusional disorder is not recognized and its rare happening restricts the ability to study genetic or other risk factors [16]. Nevertheless, small family studies have failed to detect strong genetic associations between schizophrenia and delusional disorder [17].

\section{Case Vignette}

a) An elderly and polished man was referred and hospitalized in a public psychiatric hospital, by the judge's ruling and after approval of the forensic department, for psychiatric evaluation and treatment. A few weeks earlier he had murdered his neighbor by shooting. During incarceration, some sleeplessness, alertness, aggressiveness, dubiousness, self-consciousness, selftalking, auditory hallucination, eccentric ideas and occasional argument had been observed and reported by inmates. On the other hand, there were some reports on defiant and bellicose conduct of the charged against the victim and prior lawsuits since a few years earlier. So the attorney had appealed murder during a psychotic incident. Based on the above data, unemployment during a several years before assassination, and past psychiatric history of depression, moodiness, querulousness and suspiciousness, the charged had been hospitalized with the primary diagnosis of 
Schizoaffective Disorder, Bipolar type (Schizophrenia Spectrum and Other Psychotic Disorders). After admission and first interview and Mental Status Examination (MSE), it was understandable that most of the above symptoms were related to chronic posttraumatic stress disorder (PTSD) and comorbid Persistent Depressive Disorder (Dysthymia), which was under treatment since three decades ago. Some Paranoid and Schizotypal traits, as well, were clear. The said auditory hallucination, se well, was elementary type, with no organized voice content. The murder had happened during an argument, which was not rare, by the way. The victim, as said by accused, was a boorish, but smart, neighbor in the workplace, who was jealous to his earlier social and business successes, while was aware about his psychiatric problems, too, and knew how to exasperate him without any trace, to coerce him to leave their joint office. For example, despite the fact that he was sensitive to loud sounds (hyperacusis; hyperacousia), he would generate over and over a range of sounds, whether high-pitched or low-pitched, during midnight, which could irritate him or make him paranoid, respectively, and since all these were happening in their workplace, because he was often staying there at nighttime, he could not prove them lawfully, due to lack of witness or proof. Their frequent disputes, too, were futile. Finally, the night before murder and during repetition of the said Machiavellian and unsympathetic tricks, which had made him mad, he fired him with a rifle. According to him, the abovementioned misdemeanors were among the inborn characteristics of murdered, and it was not only the assassin who was in conflict with him; qualities which were acknowledged by relatives, neighbors and colleagues, too. So, the primary diagnosis of psychosis was canceled, and referral to a supplementary criminological committee was recommended.

b) A middle age, wealthy, low-educated master mason was refereed and hospitalized in a community psychiatric hospital according to the ruling issued by the judge, for psychiatric evaluation and treatment. He was locked up due to assassination of his wife a few months before. Two consecutive forensic committees had failed to find exactly that whether the homicide had been befallen under the impact of a psychotic episode or not. So, the charged had been hospitalized with the primary diagnosis of Delusional Disorder, Jealous type (Schizophrenia Spectrum and Other Psychotic Disorders). Primary reports by law enforcement agency had presented that he had murdered his mate since he believed that she was not faithful to him, and was in an insincere, hidden extramarital relationship with another guy. So, according to constabularies' accounts, after slaying the spouse by table knife, he had tried to kill her lover, too, by going to his office, which nevertheless failed due to his flee. The alleged lover was an educated married notary, who was denying constantly any kind of passionate or sensual attachment with the victim. Neither of relatives, neighbors, or coworkers, as well, could testify such a prohibited matter. Anyways, after first reviews and MSE, the indicted said that he was suspicious to his wife since the wedding ceremony, around two decades ago, when he realized that she was not virgin. But, due to traditional and moral concerns, he kept secrecy. Ever since and despite some trivial, but manageable incidents, there was no major problem till last year. At that time, according to him, some behavioral alterations, which were not understandable, was noticeable in her. For example, she became unsympathetic, careless, bellicose, and indifferent, together with a series of absurd reasons. While he could guess the presence of another concealed improper affiliation, he could not prove that clearly, and his struggles for gathering evidence were inexplicably fruitless. Increased telephoning, pondering, grooming, and absence, with decreased dialogue and usual activities, even with respect to their kids, all were in favor of the said doubt. On the other hand, he was always certain that the kids were his own biological offspring. Mysteriousness of situation was increased when his wife took legal action, immediately after an argument, and accused him to be psychotic and delusional. If she could prove that, then she could plea for divorce, disregard to his consent. So, in the face of his susceptible social place, he started to chase her ceaselessly for a few weeks, while pretended to go on leave for a short time. At the end, he realized that she was in relationship with a notary, who was her kin's lawyer and most of all, her former lover and fucker during teenage years, data which were retrieved later during a serious argument, which ended in killing. As said by the accused, just before murder, she admitted that she loved that dude, and wanted to divorce him, because he was an uneducated and plebeian man, while she deserved to have a sophisticated and aristocratic spouse, ambitions which were confirmable, as well, by her relatives. Consequently, the primary diagnosis of psychosis was canceled, and the suspect was referred for another forensic meeting.

c) A retired officer was refereed and ordered to be hospitalized in a public psychiatric hospital, by the judge's ruling, for psychiatric evaluation and treatment. He was accused by his neighbor due to aggressive behavior, irrational mistrustfulness, repeated quarreling, and attribution of a series of transgressions, like stalking, sneaking, overhearing, and espionage to the accuser, in the last few years. Violent behavior, shouting, and fight with the law enforcement constables, too, had been recorded and filed. So, based on the existing information, and past psychiatric history of depression, self-talking, frequent illusions and suicidal attempts he had been hospitalized with the primary diagnosis of Schizoaffective Disorder, Depressive type (Schizophrenia Spectrum and Other Psychotic Disorders). During interview, the accused insisted on an intrigue, which had been scheduled by the indicter and some other unknown proprietors for confiscation of his house and properties. As said by him, the complainant and his band were jerry-builders, and he conflicted with him since a few years ago because he had 
asked him to sell or swap his house and land, while he had rejected his propose. Even the litigant and his accomplices had framed him in this regard, while, in return, he charged, also, the confronter for fabrication of evidence; brawl and litigation, which was verifiable by his lawyer, partner, caseworker, and some of local neighbors, too. So, due to lack of any true organized hallucination, delusion, disorganized speech or behavior, except than typical depressive signs and symptoms, the alleged diagnosis of psychosis was cancelled.

\section{Discussion}

Increasing complexities of contemporary era, including technologic advancements, communicative improvements, and instructive developments have caused a race between evil doings and constabulary's commitments, which are not always parallel enough and on the side of positive forces. No doubt, the said progressions have expedited the undisclosed undertakings, by anyone, including the espionage agents, party-political challengers, jealousy retaliators, vindictive avengers, romantic opponents, avaricious bankers, bunch of criminals, group of hooligans, drug dealers, smugglers, etc., the stopping of which demands huge effort and energy by the constabularies and administrators. So, while no absolute conqueror or underdog is supposable, there is a reciprocal endless game between law enforcement agencies and lawbreakers, with mutual costs and fatalities. Among various operations that are being employed by contestants, covert maneuvers play an important role because detecting them aptly or bringing them to a close fittingly, by antagonists, is not facilely possible each time [18]. So, while law enforcement agencies and courts of law demands firm proof for verification of delinquency, hidden exercises by wrongdoers obliterate such a need and substitute it with a series of made-up possibilities and conjectural deductions, which are not legitimately dependable.

Among the said furtive ploys, allegation of fake psychiatric disorders, like insanity, drug abuse, or perversion, for social defacement and elimination of rival, is a known forensic issue, especially when public opinion does not demand proof for its subjective preoccupations and can be pleased by gossips, too. In another article we reviewed the frame-up psychosis, as a common allegation in law courts, and its diagnostic and clinical issues, which must be noticed carefully by psychiatrists [2]. By taking into consideration of a variety of psychiatric signs and symptoms that maybe simulated or attributed by combating challengers (Table 1), especially in prearranged setups or stealthy movements, and by means of modern apparatuses, a question may arise with respect to accuracy or validity of psychiatric signs and symptoms in difficult situations. The first problem is the psychiatry itself, which lacks any firm biological basis for diagnosis. So, diagnosis is based essentially on clinician's apperception and deductions about the available guidelines and recommendations, like Diagnostic and Statistical Manual of Mental Disorders (DSM) [19] and International Statistical Classification of Diseases and Related Health Problems (ICD) [20], which were established descriptively and based on the phenomenological principles and psychopathology [21]; without considering any clandestine condition or appendix. For example, delusion has been identified as 'False belief', based on 'incorrect inference about external reality', that is firmly held despite objective and obvious 'contradictory proof or evidence' and even though 'other members of the culture do not share the belief' $[1,3]$.

In this regard, Jaspers regarded a delusion as a perverted view of reality, incorrigibly held. So, delusions have three components: They are held with unusual conviction and are not amenable to logic; meanwhile the absurdity or erroneousness of their content is manifest to other people. Hamilton, also, defined delusion as: false unshakable belief which arises from internal morbid processes. It is easily recognizable when it is out of keeping with the person's educational and cultural background [1]. Now, while at this juncture, 'incorrect inference about external reality' can be equal to lacking convincing proof for the examiner, respecting some suspicious misconceptions, like paranoid delusion or ideation (Table 2), how an individual can show undoubted evidence, while his or her atmosphere has been scheduled by undisclosed operations, which, typically, have been scheduled for elimination of overt hints. Now, based on the said premises, other related items like judgment and insight, as well, may be considered impaired, which, generally, indicates psychosis (Table 3).

Table 2: Essentials of Mental Status Examination (MSE) that may look impaired because of simulated or stirred signs or symptoms, which may propose existence of psychosis.

\begin{tabular}{|c|c|c|}
\hline Grounds & Definition \\
\hline Insight & $\begin{array}{c}\text { Conscious recognition of one's own condition. In psychiatry, it refers to the conscious awareness and understanding of one's } \\
\text { own psychodynamics and symptoms of maladaptive behavior; highly important in effecting changes in the personality and } \\
\text { behavior of a person. }\end{array}$ \\
\hline Judgment & $\begin{array}{c}\text { Mental act of comparing or evaluating choices within the framework of a given set of values for the purpose of electing a } \\
\text { course of action. If the course of action chosen is consonant with reality or with mature adult standards of behavior, then } \\
\text { judgment is said to be intact or normal; judgment is said to be impaired if the chosen course of action is frankly maladaptive, } \\
\text { results from impulsive decisions based on the need for immediate gratification, or is otherwise not consistent with reality as } \\
\text { meality testing }\end{array}$ & $\begin{array}{c}\text { Fundamental ego function that consists of tentative actions that test and objectively evaluate the nature and limits of the } \\
\text { environment; includes the ability to differentiate between the external world and the internal world and to accurately judge } \\
\text { the relation between the self and the environment. }\end{array}$ \\
\hline
\end{tabular}


Table 3: Plausible predisposing factors regarding the formation of fake psychiatric problems.

\begin{tabular}{|c|c|}
\hline Accelerating factors & Protective factors \\
\hline Suggestibility & Strong-mindedness \\
\hline Indifference & Inquisitiveness \\
\hline Inattentiveness & Alertness \\
\hline Taking lightly & Thoughtfulness \\
\hline Lack of knowledge & Knowledge \\
\hline Lower intelligent quotient & Higher intelligent quotient \\
\hline Extroversion & Introversion \\
\hline Paranoid traits & Paranoid traits \\
\hline Schizotypal traits & Schizoid traits \\
\hline Histrionic traits & Obsessive-compulsive traits \\
\hline Borderline traits & Narcissistic traits \\
\hline Dependent traits & Antisocial traits \\
\hline Voluptuousness or messy sexual & Asexuality, hyposexuality, \\
lifestyle & paraphilia \\
\hline Substance abusing & Abstinence \\
\hline
\end{tabular}

Also, irritability can be stirred deceitfully by dexterous plotters or accomplices, which can be the beginning of diagnosis of mood swings, irritable mood, labile mood, poor impulse control, and perhaps, bipolar disorder. On the other hand, in the era of increasing joblessness, assessment of function is becoming increasingly more difficult than before. While function, in general, should be evaluated comprehensively, including its personal, familial, social and workrelated aspects, its job-related side may easily cast a shadow on other associated pieces due to reasonable importance of monetary affairs. So, becoming a burden to kin or others, in short-term or long-term, is not always amazing. On the other hand, many persons with borderline personality trait or disorder and substance abuse problems, as well, do not show an acceptable or stable working history, which increases the bewilderment about the crucial role of function in present-day psychiatric diagnosis. Thus, any careless or non-empathic inference may bring about wrong diagnosis, based on an imaginary functional disturbance, which could be more unescapably than purposely orlazily.

On the word of literature, mental disorder is a psychiatric illness or disease whose manifestations are characterized primarily by behavioral or psychological impairment of function, measured in terms of deviation from some 'normative concept'; associated with 'distress' or 'disease', not just an 'expected response to a particular event' or limited to 'relations between a person and society'; once more, all of which may take place by means of continuous undisclosed or hectic happenings, too, for convincing, treacherously, people about the existence of a behavioral problem in an employed (functioning) or jobless (perhaps dysfunctional) person. Todays, internet and social media, which are accessible to everybody around the world, have reduced the geographical distances maximally. Broadcasting of thought (personal data), which was before imaginable only by means of media or spatially, now, is possible by personal smartphones and hackers. Therefore, non-empathetic rapport, inconsiderate attending, confused history, disorganized approach, mutual incredulousness, and messy communication between the interviewer and interviewee can stir the doubt of existence of delusion of 'thought broadcasting', an important Schneiderian symptom, in an inept clinician with respect to an examinee, who does not know how to articulate cooperatively, but safe and sound, his inferences or frame of mind. Also, presently and with increasing free social interactions between people in modern time, the schema of erotomania can be enthused easily by furtive or fooling tricks in any egoistic or stupid person. The same condition is repeatable, as well, regarding persecutory or jealous type of delusional disorder, especially in persons with paranoid personality trait or disorder (Table 3).

Likewise, now, the gap between bizarreness and nonbizarreness, as well, has been a bit washed-out, due to enhancement of masquerading skills and ways and precise analysis of circadian conduct of people, which may turn erratic syndromes like Capgras syndrome, Fregoli's phenomenon or Inter-metamorphosis into likely doubts, though foolishly (Table 2). Similarly, a worried examinee may give the impression of delusion of control or persecutory to an impatient examiner, by his or her fearful narration about stealthily watching by mysterious folks, hidden cameras, or satellites (like Google Earth). Then again, it must not be ignored that even a surely delusional person (patient) may have loads of non-delusional thoughts, too, which must be differentiated in the approved way by a proper examiner. So, clinicians should not assume that all unlikely scenarios are delusional; the veracity of a patient's beliefs should be checked before deeming their content to be delusional [3]. So, it is the duty of forensic and clinical psychiatrist to discover any kind of deceptive entrapment or simulation, in support of civil liberties and constitutional rights.

\section{Conclusion}

Technologic advancement, improvement of masquerading abilities and related apparatuses, increased availability of concealed microphones and cameras, unnoticed photographing by millions of smart phones from place to place, increasing visual surveillance for local safety or road traffic, increasing interactions via internet and social media with known or/and unknown people, increasing general scrutiny during globalization era, while can certainly set up a stable foundation for better safekeeping, scientific enhancement, cultural development, and positive interaction between people intra-nationally and internationally, have brought about an increasing possibility of conspiracy by prejudiced or inimical people, too. The said deleterious likelihood, which may occur through evil persons against blameless people, demands careful workforces, whether in law enforcement agencies, law courts, or mental health services, for alert frustration of such 
intrigues. Formal diagnostic guidelines, like ICD or DSM, have categorized, inevitably, psychiatric disorders descriptively, and trust the examiners capabilities for exact differential diagnosis between false disorders, like malingering and factitious disorder, and primary psychiatric disorders, like delusional disorder; disregard to Substance/Medication-Induced psychiatric disorders or similar problems due to Another Medical Condition. But the real things as they are not so relaxed, particularly in the existing intricate circumstances. Currently, an intrigue can be implemented so dexterously that may cause every practiced clinician to make error with respect to analysis and conclusion, especially when the last diagnosis is nevertheless based on personal inferences. So, despite the systematic description of disorders, it seems that phenomenological psychopathology needs a second look in the contemporary era, if decrement of risk of diagnostic error, parallel to descriptive approach, is a practical objective. For example:

a. The definition of delusion, as "a false belief, based on incorrect inference about external reality that is firmly held despite objective and obvious contradictory proof or evidence and even though other members of the culture do not share the belief", may be finalized by adding, for instance, "Moreover, it is not formed through furtive ploys". The same completion, or better to say notice or watchfulness, can be generalized to all other possible psychiatric signs and symptoms that may be simulated or stirred by stealthy or scheming tricks and setups, like double-crossing and masquerading scenarios, stressful circumstances, furtive or hectic arrangements, creating a scene to deceive, hack, or tampering (Table 1).

b. As like as DSM-5 that has discerned specific codes for Substance/Medication-Induced Psychiatric Disorder or Psychiatric Disorder Due to Another Medical Condition [19], forged psychiatric disorders, too, can be demarcated in the same way for improvement of diagnosis and decreasing diagnostic error.

c. While there are a number of codes in the DSM-5's section of 'Other Conditions That May Be a Focus of Clinical Attention' [19], like 'V62.4 (Z60.5) Target of (Perceived) Adverse Discrimination or Persecution', 'V62.9 (Z60.9) Unspecified Problem Related to Social Environment', 'V62.89 (Z65.4) Victim of Crime', 'V62.89 (Z65.8) Other Problem Related to Psychosocial Circumstances', 'V62.9 (Z65.9) Unspecified Problem Related to Unspecified Psychosocial Circumstances', 'V62.89 (Z65.4) Victim of Terrorism or Torture', 'V62.22 (Z65.5) Exposure to Disaster, War, or Other Hostilities', 'V62.5 (Z65.3) Problems Related to Other Legal Circumstances', which may be indirectly related to our discussion, it seems that installation of a new code with regard to fake psychiatric disorders, which have been induced as a result of hostile purposes, for drawing psychiatrist's attention to such possibility, particularly in forensic settings [22], will not be worthless.

\section{References}

1. Sims A (1998) Symptoms in the mind: an introduction to descriptive psychopathology. Bailiere Tindall, London.

2. Shoja Shafti S (2021) Frame-up Psychosis: A Dilemma in the Realm of Forensic Psychiatry. Clinical Psychology and Mental Health Care 2(3): $1-6$

3. Sadock BJ, Sadock VA, Ruiz P (2015) Delusional Disorder and Shared Psychotic Disorder. Kaplan \& Sadock's Synopsis of Psychiatry. $11^{\text {th }}$ (Edn). Philadelphia: Lippincott Wolters Kluwer pp. 330-336.

4. Marneros A, Pillman F (2004) Acute and Transient Psychoses. Cambridge: Cambridge University Press.

5. Fochtmann LJ, Mojtabai R, Bromet EJ (2009) Other psychotic disorders. In: Sadock BJ, Sadock VA, Ruiz P (Eds). Kaplan \& Sadock's Comprehensive Textbook of Psychiatry. $9^{\text {th }}($ Edn,). Philadelphia: Lippincott Williams \& Wilkins pp. 1605.

6. Fusar-Poli P, Cappucciati M, Borgwardt S (2016) Heterogeneity of psychosis risk within individuals at clinical high risk: a meta-analytical stratification. JAMA Psychiatry 73(2): 1-8.

7. Fochtmann LJ, Mojtabai R, Bromet EJ (2009) Other psychotic disorders. In: Sadock BJ, Sadock VA, Ruiz P (Eds). Kaplan \& Sadock's Comprehensive Textbook of Psychiatry. $9^{\text {th }}($ Edn,). Philadelphia: Lippincott Williams \& Wilkins pp. 1605.

8. Smith T, Horwath E, Cournos F (2010) Schizophrenia and other psychotic disorders. In: Cutler JS, Marcus ER (Eds). Psychiatry. $2^{\text {nd }}$ (Edn,). New York: Oxford University Press pp. 101.

9. Szily E, Keri S (2013) Delusion proneness and emotion appraisal in individuals with high psychosis vulnerability. Clin Psychol Psychother 20(2): 166-170.

10. Freeman D, Pugh K, Vorontsova N, Antley A, Slater M, et al. (2010) Testing the continuum of delusional beliefs: An experimental study using virtual reality. J Abnorm Psychiatry 119(1): 83-92.

11. Mishara AL, Fusar-Poli P (2013) The phenomenology and neurobiology of delusion formation during psychosis onset: Jaspers, Truman symptoms, and aberrant salience. Schizophrenia Bulletin 39(2): 278286.

12. Tondo L, Vázquez GH, Baethge C (2016) Comparison of psychotic bipolar disorder, schizoaffective disorder, and schizophrenia: an international, multisite study. Acta Psychiatr Scand 133(1): 34-43.

13. Nykiel SA, Baldessarini RJ, Bower MC, Goodwin J, Salvatore P (2008) Psychosis NOS: search for diagnostic clarity. Harv Rev Psychiatry 16: 55.

14. Kendler KS (1982) Demography of paranoid psychosis (delusional disorder). Arch Gen Psychiatry 39: 890.

15. Fusar-Poli P, Cappucciati M, Bonoldi I (2016) Prognosis of brief psychotic episodes: a meta analysis. JAMA Psychiatry 73: 211-220.

16. Mojtabai R, Fochtmann L, Bromet EJ (2017) Other Psychotic Disorders. In: Sadock BJ, Sadock VA, Ruiz P, (Eds,). Kaplan \& Sadock's Comprehensive Textbook of Psychiatry. $10^{\text {th }}($ Edn). Philadelphia: Wolters Kluwer pp. 1582-1587.

17. Fennig S, Craig TJ, Bromet EJ (1996) The consistency of DSM-III-R delusional disorder in a first admission sample. Psychopathology 29: 315 .

18. Shoja Shafti S (2021) SET-UP Madness: A Review. ASEAN Journal of Psychiatry 22(2): 1-8.

19. (2013) Psychiatric Association (APA). Diagnostic and Statistical Manual of Mental Disorders. $5^{\text {th }}$ ed. Washington, DC: American Psychiatric Association. 
20. (2011) World Health Organization. International Statistical Classification of Diseases and Related Health Problems, $10^{\text {th }}$ Revision. Geneva: World Health Organization.

21. Shoja Shafti S (2021) Diagnostic Review of an Important Criminal Dilemma: Entrapment Madness. Annals of Clinical Cases 2(2): 37-41.

\section{ISSN: 2574-1241}

DOI: 10.26717/BJSTR.2021.36.005923

Saeed Shoja Shafti. Biomed J Sci \& Tech Res

(c) (P) This work is licensed under Creative

Submission Link: https://biomedres.us/submit-manuscript.php
22. Watson C, Eth S, Leong GB (2017) Clinical-Legal Issues in Psychiatry. In: Sadock BJ, Sadock VA, Ruiz P (Eds.), Kaplan \& Sadock's Comprehensive Textbook of Psychiatry. $10^{\text {th }}($ Edn). Philadelphia: Wolters Kluwer pp. 4427-4439.

$\begin{array}{ll}\text { BIOMEDICAL } & \text { Assets of Publishing with us } \\ \text { RESEARCHES } & \text { - Global archiving of articles } \\ \text { - Immediate, unrestricted online access }\end{array}$

